\title{
CORRESPONDENCE:
}

\section{Managing exposure to flooding in New York City}

To the Editor - Writing in Nature Climate Change, Lin and colleagues ${ }^{1}$ show that the combined effect of storm climatology and sea-level rise will greatly shorten surge-flooding return periods. Future climate effects may cause the present-day $100-y r$ and 500-yr surge flooding in New York City (NYC) to occur every 3-20 yrs and every 25-240 yrs, respectively. These results are important for managing flood risk in NYC. However, apart from changes in the flood hazard, the exposure of buildings, people and infrastructure also largely contributes to heightened flood risk in NYC. Over 33,000 and 66,000 buildings are located in the 100-yr and 500 -yr flood zones, respectively, which represent a value of US $\$ 18.3$ billion to US $\$ 22.3$ billion. Recent research shows that, over the past 100 years, the value at risk in flood zones in NYC has increased by a factor of four to seven (Fig. 1) ${ }^{2}$. This trend is likely to continue, because NYC's population is projected to grow from over 8.2 million in 2006 to 9.1 million in 2030 (ref. 3). Both the value at risk in flood zones and population growth are global trends, and many other coastal cities around the world are facing the same challenge of increasing flood risk $^{4}$, as vulnerable city waterfronts are increasingly being seen as 'multifunctional locations' for economic, environmental and social activities ${ }^{5}$.

These figures provide a rationale for a comprehensive adaptation strategy that focuses not only on the flood hazard, as outlined by Lin and colleagues ${ }^{1}$, but also on managing trends in exposure through fine-tuning flood insurance, building codes and zoning policies. The US National Flood Insurance Program (NFIP) insures a value of about US $\$ 8$ billion in NYC at present and is an important programme for achieving risk reduction ${ }^{6}$. For example, the NFIP requires that new structures should be elevated to the expected water level of a 100-yr flood. According to Lin and colleagues ${ }^{1}$, at least parts of the 500-yr zone may change into the 100 -yr flood zone. However, the NFIP does not address climate change, and its

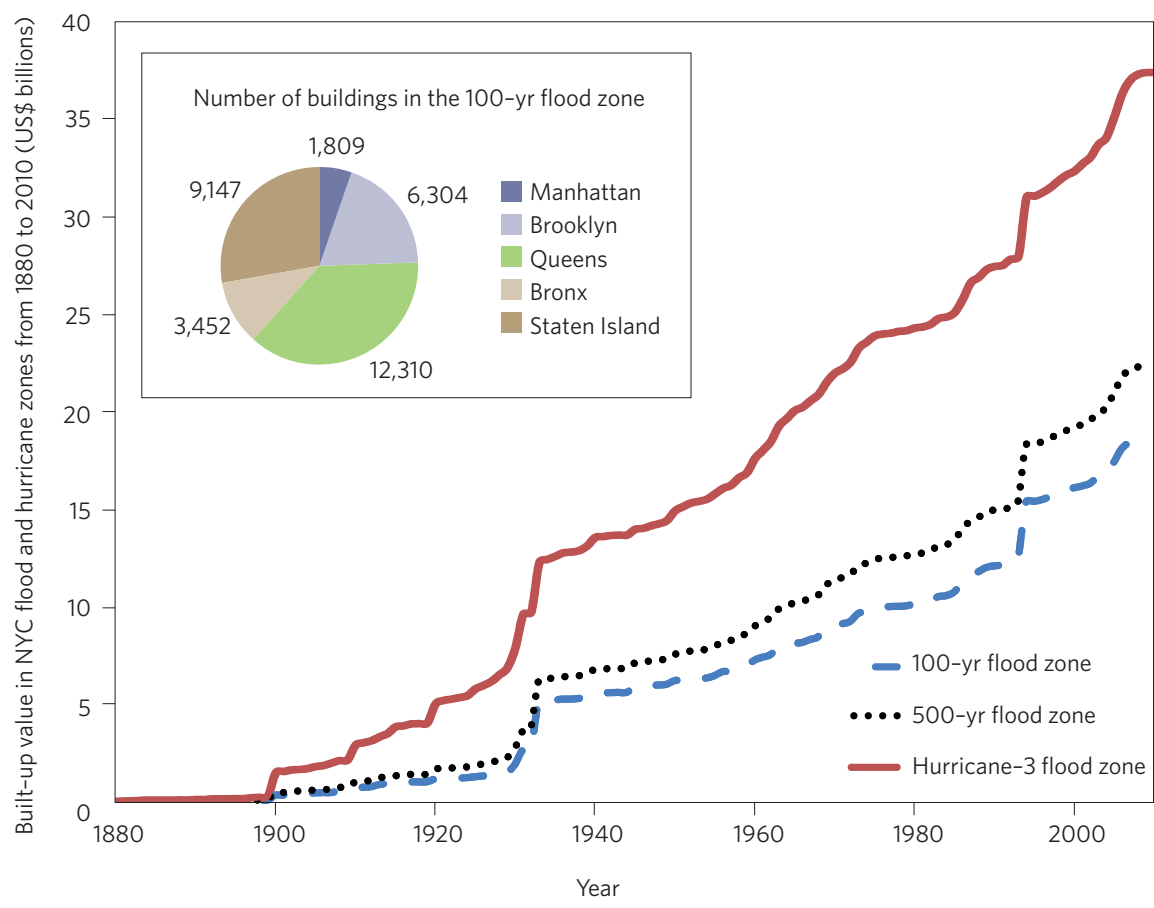

Figure 1 | Cumulative values of the properties at risk in the 100-yr, 500-yr and hurricane-3 flood zones from 1880 to 2010 (all in 2009 values, in US $\$$ billion). Inset: Number of buildings in the 100 -yr flood zone, distributed per NYC borough².

regulations are restricted to the current 100 -yr flood zone. For buildings in the 500 -yr flood zone, minimum elevation requirements do not apply. We, therefore, propose that insurance and the city's building-code regulations should be applied to what is expected to be the future 100-yr flood zone, and a buildingcode policy should be formulated that requires 'freeboard' (building above the 100-yr flood level) of up to 2 or $3 \mathrm{ft}$ for new structures in the 100-yr flood zone. It has been demonstrated that investing in (additional) freeboard can be cost-effective in terms of the reduced risk it delivers ${ }^{7}$. Moreover, zoning controls could be applied to limit potential flood damage, for example, by imposing building restrictions or by increasing the required 'open space ratio', which implies a lower building footprint and, hence, lower potential flood damage ${ }^{2}$.

References

1. Lin, N., Emanuel, K., Oppenheimer, M. \& Vanmarcke, E. Nature Clim. Change 2, 462-467 (2012).

2. Aerts, J. C. J. H. \& Botzen, W. J. W. Ann. N.Y. Acad. Sci. 1227, 1-82 (2011).

3. NYC-DCP New York City Population Projections by Age/Sex and Borough (2030 briefing booklet, New York City Department of City Planning, 2006).

4. Rosenzweig, C., Solecki, W., Hammer, S. A. \& Mehrotra, S. Nature 467, 909-911(2010).

5. Nicholls, R. J. \& Cazenave, A. Science 328, 1517-1520 (2010).

6. Michel-Kerjan, E. \& Kunreuther, H. Science 333, 408-409 (2011)

7. Jones, C. P., Coulborne, W. L., Marshall, J. \& Rogers, S. M. Evaluation of the National Flood Insurance Program's Building Standards (American Institutes for Research, 2006).

Jeroen C. J. H. Aerts ${ }^{\star}$ and W. J. Wouter Botzen Institute for Environmental Studies, VU University Amsterdam, De Boelelaan 1087, 1081 HV Amsterdam, The Netherlands.

*e-mail: jeroen.aerts@ivm.vu.nl 